\title{
Pcsk9 is associated with severity of coronary artery lesions in male patients with premature myocardial infarction
}

\author{
Jing Gao ${ }^{1,2,{ }^{+}}$, Ya-Nan Yang ${ }^{4 \dagger}$, Zhuang Cui ${ }^{4}$, Si-Yuan Feng ${ }^{4}$, Jing Ma ${ }^{3}$, Chang-Ping Li ${ }^{4^{*}}$ and Yin $\mathrm{Liu}^{2,5^{*}}$ (D)
}

\begin{abstract}
Background: Proprotein convertase subtilisin/kexin type 9 (Pcsk9) correlated with incidence and prognosis of coronary heart disease. However, it is unclear whether Pcsk9 contributed to coronary artery lesion severity in patients with premature myocardial infarction (PMI). The present study investigated associations between Pcsk9 and coronary artery lesion severity in PMl patients who underwent coronary angiography (CAG).

Methods: This prospective cohort study included young men (age $\leq 45$ years, $n=332$ ) with acute MI who underwent CAG between January 2017 and July 2019. Serum Pcsk9 levels and clinical characteristics were evaluated. SYNTAX scores (SYNergy between percutaneous coronary intervention with [paclitaxel-eluting] TAXUS stent and cardiac surgery) were calculated to quantify coronary artery lesions.

Results: Serum Pcsk9 levels were positively associated with SYNTAX scores $(r=0.173, P<0.05)$. The diagnostic cutoff value of PSCK9 level was $122.9 \mathrm{ng} / \mathrm{mL}$, yielding an area under the curve (AUC) of 0.63 , sensitivity $81 \%$, and specificity 40\%. Serum Pcsk9, LDL-C, Apob, NT-proBnp, CK level, and diabetes history were independent predictors of high SYNT AX scores $(P<0.05)$. After stratifying by serum $L D L-C$ level (cutoff $=2.6 \mathrm{mmol} / \mathrm{L}$ ), medium-high Pcsk9 levels had increased risk of high SYNTAX scores in patients with high LDL-C $(P<0.05)$, and higher serum Pcsk9 levels had increased risk of major adverse cardiac events (MACE) after adjusting for confounding factors $(P<0.05)$.
\end{abstract}

Conclusion: Serum Pcsk9 levels correlates with severity of coronary artery lesion in PMl patients and may serve as a biomarker for severity of coronary artery stenosis in this patient population, which may contribute to risk stratification.

Keywords: Coronary angiography, Coronary artery disease, Premature myocardial infarction, Proprotein convertase subtilisin/kexin type 9

\section{Background}

The high incidence and mortality of myocardial infarction (MI) pose a threat to public health. More than 600, 000 people have experienced myocardial infarction, which causes 180,000 deaths each year in China [1,2].

\footnotetext{
* Correspondence: lichangping@tmu.edu.cn; liuyin2088@163.com

${ }^{+}$Jing Gao and Ya-Nan Yang are co-first authors.

${ }^{4}$ Tianjin Medical University, No.22 Qi xiangtai Road, Heping District, Tianjin 300070, P.R. China

${ }^{2}$ Thoracic Clinical College, Tianjin Medical University, No.22 Qi xiang tai Road, Heping District, Tianjin 300070, P.R. China

Full list of author information is available at the end of the article
}

In recent years, the incidence of premature myocardial infarction (PMI) has gradually increased [3]. PMI is generally defined as MI for men $\leq 55$ years and women $\leq 65$ years [4]. Arora et al. [5] found that the proportion of young patients hospitalized for acute MI increased significantly from 27 to 32\% between 1995 and 2014, and 1 -year mortality of younger patients with AMI was nearly $10 \%$. Genetics play a critical role in the progression of PMI, with a heritability of 63\% [6]. Additional evidence reveals that proprotein convertase subtilisin/ kexin type 9 (Pcsk9) relates to cholesterol homeostasis,

C C The Author(s). 2021 Open Access This article is licensed under a Creative Commons Attribution 4.0 International License, which permits use, sharing, adaptation, distribution and reproduction in any medium or format, as long as you give appropriate credit to the original author(s) and the source, provide a link to the Creative Commons licence, and indicate if changes were made. The images or other third party material in this article are included in the article's Creative Commons licence, unless indicated otherwise in a credit line to the material. If material is not included in the article's Creative Commons licence and your intended use is not permitted by statutory regulation or exceeds the permitted use, you will need to obtain permission directly from the copyright holder. To view a copy of this licence, visit http://creativecommons.org/licenses/by/4.0/ The Creative Commons Public Domain Dedication waiver (http://creativecommons.org/publicdomain/zero/1.0/) applies to the data made available in this article, unless otherwise stated in a credit line to the data. 
is a risk factor for PMI [7-9]. As a relatively new PMI risk factor, Pcsk9 has received widespread attention for elevating plasma low-density lipoprotein cholesterol levels due to promote degradation of LDL receptor in the liver $[10,11]$. Pcsk9 is related to incidence and prognosis of coronary artery disease (CAD) and with lipid or non-lipid cardiovascular risk factors [12-14]. The increasing clinical application of Pcsk9 inhibitors is considered to be an effective treatment to reduce major adverse cardiovascular events (MACE), MI and stroke, which has not a significant safety concerns $[15,16]$.

Various scoring systems are used to assess the extent of CAD, including SYNergy between percutaneous coronary intervention with TAXus and cardiac surgery (SYNTAX) [17], and Gensini and Jeopardy scores [18]. According to the 2018 ESC/EACTS guidelines [19], SYNTAX score was applied to assess the coronary artery lesion. Results of multiple studies indicate that Pcsk9 may be associated with CAD severity and plaque load [20-24]. A few studies have determined association of Pcsk9 levels with the extent of CAD [22, 25], although this relationship remains controversial. To date, no study has investigated correlations between Pcsk9 and CAD severity in PMI patients. Therefore, this study aimed to determine association of Pcsk9 with CAD severity in patients with PMI.

\section{Materials and methods}

\section{Study population}

This prospective study included 332 patients (aged $\leq 45$ years) diagnosed with acute MI according to the Fourth Universal Definition of Myocardial Infarction [26] or the International Classification of Diseases, 10th revision, Clinical Modification (ICD-10-CM) codes (ICD-10-CM I21). Patients were recruited from the cardiac/coronary care unit of Tianjin Chest Hospital, China, from January 2017 to July 2019. Inclusion criteria were: patients aged $\geq 18$ years presenting within 1 day (preferably within $12 \mathrm{~h}$ ) after pain onset with a principle diagnosis of non-ST elevation myocardial infarction (NSTEMI), or ST-elevation myocardial infarction (STEMI). Enrolled patients had at least one of the following criteria: (i) ECG ischemic changes such as persistent or dynamic ST-segment deviation, T-waves inversion, new left bundle branch block; (ii) evidence of positive conventional or high-sensitive troponin by local laboratory reference values with a rise and/or fall in enzyme levels; (iii) patients who underwent coronary angiography (CAG), had one or more coronary artery stenosis (stenosis $\geq 50 \%$ ), and received percutaneous coronary intervention (PCI) within $12 \mathrm{~h}$. Exclusion criteria were: subjects with prior coronary artery bypass graft (CABG) surgery, female, antihyperlipidemic agents within 3 months, infectious, systemic inflammatory disease, or severe hepatic and/or renal failure.

\section{Ethical considerations}

The study protocol was approved by the Ethics Committee of Tianjin Chest Hospital (No. 2017KY-007-01) and all included patients provided signed informed consent prior to study participation. All procedures performed were in accordance with the ethical standards of the Helsinki Declaration and its later amendments, or comparable ethical standards.

\section{Measurement of clinical and laboratory parameters}

A data checklist included demographic information, medical history (hypertension, diabetes, familial history of premature coronary artery disease, and history of tobacco smoking), body mass index (BMI), blood pressure (BP), left ventricular ejection fraction (LVEF) based on echocardiography. Conventional risk factors for CAD, including hypertension [27], diabetes [28], and smoking status [29] were evaluated. Laboratory parameters were measured by standard clinical laboratory techniques. Blood samples were taken after an overnight fasting ( $\geq 8 \mathrm{~h}$ ) on the day of admission to determine serum levels of apolipoprotein $B$ (ApoB), total cholesterol (TC), low-density lipoprotein cholesterol (LDL-C), high-density lipoprotein cholesterol (HDL-C), triglycerides (TG), alanine transaminase (ALT), creatinine, high-sensitivity C-reactive protein (hs-Crp) and $\mathrm{N}$-terminal pro-B type natriuretic peptide (NT-proBnp).

\section{Measurement of Pcsk9}

After overnight fasting ( $\geq 8 \mathrm{~h}$ ) on the day of admission, blood samples were collected in tubes with EDTA anticoagulant (ethylene diamine tetra-acetic acid) in the morning and centrifuged at $3000 \mathrm{rpm}$ at $4{ }^{\circ} \mathrm{C}$ for $10 \mathrm{~min}$ to obtain serum. All samples were stored at $-80^{\circ} \mathrm{C}$ until analysis. Serum Pcsk9 levels were analyzed by enzyme linked immunosorbent assay (ELISA) (R\&D Systems, Minneapolis, MN, USA) and samples were diluted 1:1 in dilution buffer prior to assay.

\section{SYNTAX scores}

Angiographic images of all patients were evaluated and SYNTAX scores (SS) were calculated. SS is a tool for grading complexity and severity of $\mathrm{CAD}$ based on angiography. It is an anatomical scoring system that quantitatively characterizes coronary arteries based on location, function, complexity and number of obstructions, evaluating vessels with diameters greater than 1.5 $\mathrm{mm}$ and stenosis greater than $50 \%$. Each segment of the coronary artery has a weighting factor determined by lesion location and severity. A SYNTAX calculator (www. syntaxscore.com) is used to synthesize lesion features to obtain final scores. The SYNTAX scores were assessed by three experienced cardiologists who were blinded to Pcsk9 concentrations. If disagreement occurs, final decisions are determined by consensus. 


\section{Patient follow-up and main outcomes}

According to CAG, all patients received appropriate treatment modalities (including PCI) from their cardiologists. Patients were followed prospectively at $6,12,24,36$ months after diagnosis. The primary outcome included cardiac death, non-fatal stroke, non-fatal recurrent myocardial infarction, post-discharge revascularization (PCI/ CABG), and re-hospitalization for heart failure. Cardiac death was confirmed by death from cardiac causes, including sudden cardiac death, congestive HF, acute MI, severe arrhythmia, stroke, or other structural/functional cardiac diseases. Stroke was defined as an acute cerebral infarction on the basis of imaging results or typical symptoms. MI was diagnosed based on a comprehensive evaluation combining equivalent symptom complex or chest pain, changes in cardiac enzyme levels, and electrocardiogram findings.

\section{Statistical analysis}

Statistical analysis was carried out using SPSS 25 software (SPSS Inc., Chicago, Illinois, USA). Before applying the corresponding test, the normality of the distribution in variables have been verified. The normality of all continuous variables were verified by Kolmogorov-Smirnov test. Tertiles were used for the scoring system ( $\mathrm{SS} \leq 12$,> $12<\mathrm{SS} \leq 21.5, \mathrm{SS}>21.5)$. The results were expressed as percentage, mean $( \pm S D)$ or median (IQR). Comparison of continuous variables between groups were performed by One-way analysis of variance (ANOVA) or KruskalWallis tests. Comparison of categorical variables between the group were performed by Chi-square analysis. Spearman correlation test was used to determine relationships between targeted parameters. Multivariate logistic regression analysis was used to calculate odds ratios (ORs) of high SYNTAX scores (> 21.5) for patients with tertile 2 (T2) and tertile 3 (T3) versus patients with tertile 1 (T1) grouped according to Pcsk9 levels. The model was also adjusted for various factors. Significant parameters in univariate analysis $(P$-value $<0.05)$ were entered into multivariate linear regression analysis to determine the predictors of SYNTAX scores. Univariate and multivariate Cox regression analyses were performed to calculate hazard ratios (HRs) of MACE. A Kaplan-Meier curve was graphed for MACE-free survival times of patients by $\mathrm{T} 1, \mathrm{~T} 2$, and $\mathrm{T} 3$ grouped according to Pcsk9 levels. All tests were two-sided and $P<0.05$ was considered statistically significant.

\section{Results}

\section{Predictive factors for SYNTAX scores}

Angiography results of PMI patients showed that 145 patients (43.70\%) had one vessel lesion, 100 patients (30.10\%) had two vessel lesions, and 87 patients (26.20\%) had three vessel lesions. PMI patients were grouped into
3 subgroups by SYNTAX scores (Table 1). All patients did not have familial hypercholesterolemia, prior statin use, and prior ezetimibe use, while34 patients $(10.30 \%)$ had familial premature coronary artery disease (PCAD), 44 patients (13.30\%) had history of beta-blocker use, 34 patients $(13.30 \%)$ had history of CCB use, 32 patients (9.70\%) had history of ARB/ACEI use. However, proportions of familial PCAD, beta-blocker use, CCB use, and ARB/ACEI use were not significant difference between the three groups (all $P>0.05$ ). Particularly, LVEF, diabetes history, and serum LDL-C, ApoB, glucose, and Pcsk9 levels were significantly different between these subgroups (all $P<0.05$ ). Proportions of diabetes history, serum LDL-C, ApoB, glucose and Pcsk9 levels were highest in the SS $>21.5$ group, while the proportion of LVEF was lowest in the SS $>21.5$ group. Predictors of SYNTAX scores were identified by univariate linear regression analysis $(P<0.05$, Table 2$)$. Subsequently, multivariate linear regression analysis indicated that serum Pcsk9, Apob, NT-proBnp and CK levels and diabetes history were positively associated with high SYNTAX scores (all $P<0.05)$.

\section{Pcsk9levels and CAD severity}

Associations between serum Pcsk9 levels and SYNTAX scores were shown in Fig. 1a $\left(r_{s}=0.167, P<0.05\right)$. The diagnostic cutoff value of PSCK9 level for medium-high SYNTAX was $122.9 \mathrm{ng} / \mathrm{mL}$, yielding an area under the curve (AUC) of 0.63 , sensitivity $81 \%$, and specificity $40 \%$ (Supplementary Figure 1). Compared to the low SYNT AX score groups (SS $\leqq 12$ and $12<\mathrm{SS} \leqq 21.5$, respectively), serum Pcsk9 levels were increased in the high SYNTAX score group (SS $>21.5) \quad(P<0.05$, Fig. $1 b)$. Serum Pcsk9 levels were grouped as 3 tertiles, and were then evaluated for associations between high SYNTAX scores in PMI patients. Medium $(122.92 \leqq$ Pcsk $9<204.13 \mathrm{ng} / \mathrm{mL})$ and high (Pcsk9 $\geqq 204.13 \mathrm{ng} / \mathrm{mL}$ ) Pcsk9 groups had greater risk of having high SYNTAX scores $($ SS $>21.5$ ) than those in the low Pcsk9 group (Pcsk9 $<122.92 \mathrm{ng}$ / $\mathrm{mL}$ ), either un-adjusted or adjusted for confounding factors (all $P<0.05$, Fig. 2).

Serum Pcsk9 was positively correlated with LDL-C levels $(r=0.138, P<0.05)$, while serum Pcsk9 was not correlated with Apob levels $(r=0.092, P=0.175)$ (Fig. 1c and d). After stratifying by serum LDL-C level (cutoff $=2.6$ $\mathrm{mmol} / \mathrm{L}$ ), multivariate logistic regression analysis indicated that medium Pcsk9 levels had a greater risk of high SYNTAX scores in patients with high LDL-C levels, which were unadjusted or adjusted for confounding factors (all $P<0.05$, Supplementary Table 1 ). This observation was not found in patients with low LDL-C levels after being unadjusted or adjusted for confounding factors (all $P>$ 0.05, Supplementary Table 1). 
Table 1 Baseline clinical, demographic, biochemical and angiographic features of patients in different SYNTAX score (SS) groups

\begin{tabular}{|c|c|c|c|c|c|}
\hline Variables & Total $(N=332)$ & SS $\leq 12(n=114)$ & $12<\mathrm{SS} \leq 21.5(n=113)$ & SS $>21.5(n=105)$ & $P$-value \\
\hline Age (years) & $39.30(4.50)$ & $39.30(4.70)$ & $39.60(4.70)$ & $39.10(3.90)$ & 0.57 \\
\hline Body mass index, $\mathrm{kg} / \mathrm{m} 2$ & $25.00(2.51)$ & $25.28(2.70)$ & $24.64(2.30)$ & $25.06(2.51)$ & 0.46 \\
\hline SBP, mmHg & $132.50(23.20)$ & $132.80(21.40)$ & $133.20(24.30)$ & $131.30(24.20)$ & 0.96 \\
\hline DBP, mmHg & $81.0(14.7)$ & $80.2(14.5)$ & $84.1(15.1)$ & $78.5(14.2)$ & 0.07 \\
\hline \multicolumn{6}{|l|}{ Past history } \\
\hline Hypertension & $148(44.60)$ & $44(39.00)$ & $49(43.40)$ & $55(52.10)$ & 0.26 \\
\hline Diabetes & $46(13.80)$ & $8(7.00)$ & $12(10.60)$ & $27(25.70)$ & $<0.01^{*}$ \\
\hline Familial hypercholesterolemia & $0(0)$ & $0(0)$ & $0(0)$ & $0(0)$ & - \\
\hline Familial PCAD & $34(10.30)$ & $16(14.00)$ & $9(8.00)$ & $9(8.60)$ & 0.36 \\
\hline Smoking & $256(77.10)$ & $89(78.10)$ & $83(73.50)$ & $84(80.00)$ & 0.63 \\
\hline \multicolumn{6}{|l|}{ Ml type } \\
\hline STEMI & $289(87.10)$ & $95(83.30)$ & $96(85.00)$ & $98(93.30)$ & 0.18 \\
\hline NSTEMI & $43(12.90)$ & $19(16.70)$ & $17(15.00)$ & $7(6.70)$ & \\
\hline \multicolumn{6}{|l|}{ Biochemistry } \\
\hline White blood cells, $10^{9} / \mathrm{L}$ & $11.45(3.12)$ & $11.23(3.29)$ & $11.20(2.56)$ & $11.95(3.46)$ & 0.21 \\
\hline Urea, mmol/L & $4.69(1.64)$ & $4.48(2.34)$ & $4.55(1.70)$ & $5.05(1.89)$ & 0.05 \\
\hline Lp(a), nmol/L & $21.15(51.38)$ & $19.00(33.65)$ & $18.05(51.58)$ & $24.95(53.63)$ & 0.28 \\
\hline $\mathrm{TC}, \mathrm{mmol} / \mathrm{L}$ & $5.01(1.12)$ & $4.84(0.98)$ & $4.98(1.19)$ & $5.22(1.16)$ & 0.11 \\
\hline $\mathrm{LDL}-\mathrm{C}, \mathrm{mmol} / \mathrm{L}$ & $3.35(1.04)$ & $3.18(0.92)$ & $3.26(0.98)$ & $3.63(1.17)$ & $0.02^{*}$ \\
\hline VLDL-C, mmol/L & $0.49(0.48)$ & $0.55(0.53)$ & $0.48(0.48)$ & $0.49(0.43)$ & 0.87 \\
\hline $\mathrm{HDL}-\mathrm{C}, \mathrm{mmol} / \mathrm{L}$ & $0.96(0.31)$ & $0.98(0.42)$ & $0.92(0.25)$ & $0.97(0.20)$ & 0.25 \\
\hline Triglycerides, mmol/L & $2.11(1.49)$ & $2.12(1.35)$ & $2.11(1.53)$ & $2.09(1.42)$ & 0.99 \\
\hline Apob, g/L & $1.20(0.30)$ & $1.15(0.27)$ & $1.17(0.29)$ & $1.29(0.32)$ & $<0.01^{*}$ \\
\hline$A L T, U / L$ & $54.10(41.55)$ & $48.75(47.45)$ & $55.55(39.98)$ & $54.5(41.78)$ & 0.97 \\
\hline Glucose, mmol/L & $5.62(2.93)$ & $5.52(1.88)$ & $5.51(2.35)$ & $6.52(4.06)$ & $0.04^{*}$ \\
\hline Creatinine, $\mu \mathrm{mol} / \mathrm{L}$ & $79.54(19.74)$ & $77.56(12.30)$ & $76.96(16.82)$ & $84.44(27.16)$ & 0.09 \\
\hline \multicolumn{6}{|l|}{ Coronary heart disease } \\
\hline LVEF, \% & $49.80(7.70)$ & $51.30(7.10)$ & $50.40(7.80)$ & $47.60(7.70)$ & $<0.01^{*}$ \\
\hline Creatine kinase, U/L & $1649.50(2451.00)$ & $1324.00(1903.00)$ & $1744.00(2332.80)$ & $1950.00(2674.00)$ & 0.18 \\
\hline CK-MB, U/L & $125.5(189.8)$ & $111.5(184.0)$ & $121.0(174.0)$ & $162.0(249.0)$ & 0.33 \\
\hline c-Tnt, ng/mL & $3.57(5.14)$ & $2.61(5.38)$ & $3.47(4.62)$ & $4.01(5.14)$ & 0.15 \\
\hline hs-Crp, mg/L & $6.18(13.01)$ & $6.70(15.04)$ & $5.55(11.68)$ & $5.92(13.06)$ & 0.88 \\
\hline NT-proBnp, pg/mL & $446.0(832.4)$ & $407.6(809.8)$ & $437.5(789.5)$ & $528.1(905.2)$ & 0.29 \\
\hline \multicolumn{6}{|l|}{ Prior drug use } \\
\hline Statin & $0(0)$ & $0(0)$ & $0(0)$ & $0(0)$ & - \\
\hline Ezetimibe & $0(0)$ & $0(0)$ & $0(0)$ & $0(0)$ & - \\
\hline Beta-blocker & $44(13.30)$ & $16(14.00)$ & $14(12.40)$ & $14(13.30)$ & 0.22 \\
\hline$C C B$ & $34(10.20)$ & $11(9.70)$ & $14(12.40)$ & $9(8.60)$ & 0.45 \\
\hline ARB/ACEl & $32(9.70)$ & $9(7.90)$ & $11(9.70)$ & $12(11.40)$ & 0.31 \\
\hline
\end{tabular}

Biomarker

Pcsk9, ng/mL

Variables are presented as mean (SD), median (IQR), or $\mathrm{n}(\%), P$-values were derived from one-way analysis of variance, the Kruskal-Wallis test or $\mathrm{X} 2$ test. ${ }^{*} P<0.05$ $S B P$ systolic blood pressure, $D B P$ diastolic blood pressure, $P C A D$ premature coronary artery disease, $L p(a)$ lipoprotein a, $T C$ total cholesterol, $L D L-C$ low density lipoprotein cholesterol, $A p o b$ apolipoprotein $B, H D L-C$ high density lipoprotein cholesterol, $A L T$ alanine transaminase, $L V E F$ left ventricular ejection fraction, $C K-M B$ creatine kinase MB, $h s$-Crp high-sensitivity C-reactive protein, $c$-Tnt cardiac Troponin T, NT-proBnp N-terminal pro-B type natriuretic peptide, $C C B$ calcium channel blocker, $A R B / A C E I$ angiotensin receptor blocker/angiotensin converting enzyme inhibitor, $P c s k 9$ proprotein convertase subtilisin/kexin type $9 .{ }^{*} P<0.05$ 
Table 2 Univariate and multivariate linear regression analysis of SYNTAX score and predictors

\begin{tabular}{|c|c|c|c|c|}
\hline \multirow[t]{2}{*}{ Predictors } & \multicolumn{2}{|c|}{ Univariate } & \multicolumn{2}{|c|}{ Multivariate } \\
\hline & $\beta$ & $P$-value & $\beta$ & $P$-value \\
\hline Pcsk9, ng/mL & 0.017 & $0.010^{*}$ & 0.013 & $0.027^{*}$ \\
\hline Apob, $g / L$ & 5.778 & $0.004^{*}$ & 4.559 & $0.020^{*}$ \\
\hline Glucose, $\mathrm{mmol} / \mathrm{L}$ & 0.393 & $0.028^{*}$ & - & - \\
\hline Creatine kinase, $\mu \mathrm{mol} / \mathrm{L}$ & 0.001 & $<0.001^{*}$ & 0.001 & $0.001^{*}$ \\
\hline c-Tnt, ng/mL & 0.511 & $0.005^{*}$ & - & - \\
\hline NT-proBnp, pg/mL & 0.001 & $0.021^{*}$ & 0.002 & $0.011^{*}$ \\
\hline LVEF, \% & -0.280 & $<0.001^{*}$ & - & - \\
\hline LDL-C, mmol/L & 1.516 & $0.008^{*}$ & - & - \\
\hline Diabetes & 5.091 & $0.003^{*}$ & 3.869 & $0.025^{*}$ \\
\hline
\end{tabular}

Pcsk9 proprotein convertase subtilisin/kexin type 9, Apob apolipoprotein B, cTnt cardiac Troponin T, NT-proBnp N-terminal pro-B type natriuretic peptide, LVEF left ventricular ejection fraction, $L D L-C$ low density lipoprotein cholesterol. ${ }^{*} P<0.05$

\section{Pcsk9 level and MACE}

Three hundred sixteen patients were followed up (16 patients were lost to follow-up) for the occurrence of MACE (Supplementary Table 2). After 1-year follow-up, 40 patients had occurrence of MACE, which included 3 cardiac deaths, 4 non-fatal recurrent myocardial infarctions, 26 target lesion revascularizations, 7 heart failures, and 3 strokes. Serum Pcsk9, TG, and SBP increased significantly in patients with MACE compared to levels in patients without MACE (Supplementary Table 2). After adjusting for confounding factors, univariate Cox regression analysis indicated that high levels of Pcsk9, creatinine, glucose, blood urea nitrogen (BUN) and SBP significantly associated with high risk of MACE in PMI patients (Table 3). Subsequent multivariate Cox regression analysis indicated that elevating Pcsk9 levels were associated with high risk of MACE $(P<0.05$, Table 3$)$. Similarly, patients with high Pcsk9 levels $(\geqq 204.13 \mathrm{ng} /$ $\mathrm{mL}$ ) had a high risk of MACE compared with those with low Pcsk9 levels $(<122.92 \mathrm{ng} / \mathrm{mL})$ by univariate Cox regression analysis, but without statistical significance (HR $=2.28, P=0.08$, Table 3). Compared to patients with low serum Pcsk9 levels, patients with high serum Pcsk9 levels had lower MACE-free probability after 50-months follow-up, but without statistical significance $(85 \%$ vs $65 \%, P=0.20$, Supplementary Figure 2).

\section{Discussion}

CHD is a globally leading cause of death [30], however, the studies focusing on PMI are lacking. PMI accounts for about $27.7 \%$ of MI patients in China [31]. MI may be devastating, particularly in patients with young age due to its greater impact on patients' psychological status, ability to work and the socioeconomic burden. The present study expanded previous findings and is the first study to establish a correlation of serum Pcsk9 levels and coronary artery lesions (indicated by SYNTAX

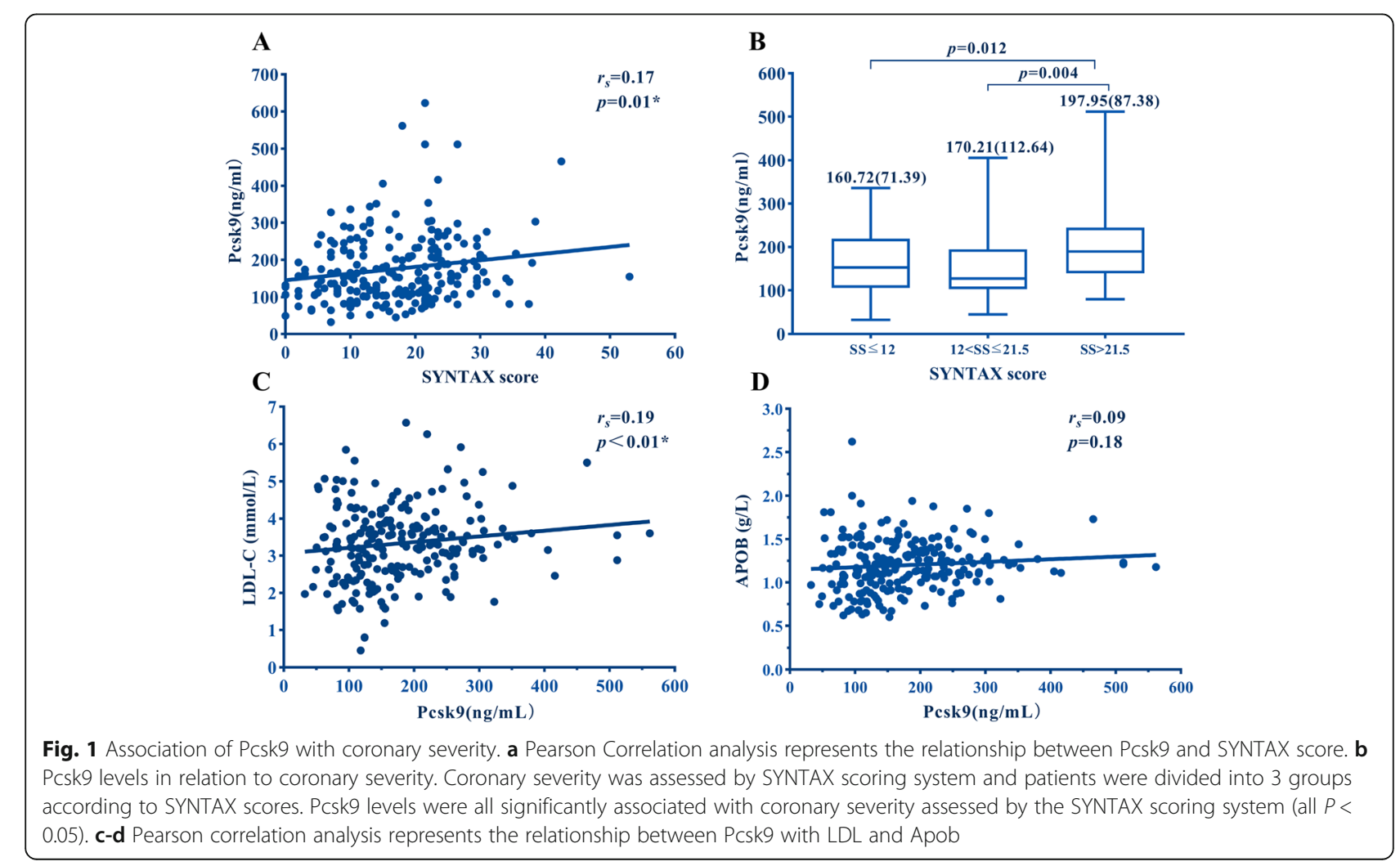




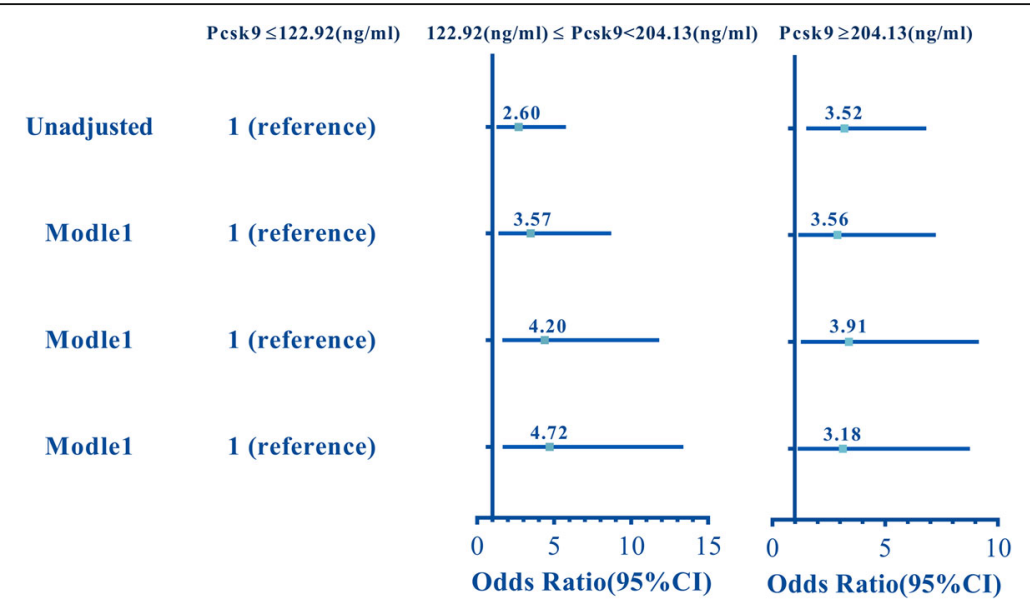

Fig. 2 Risk of high SYNTAX scores in patients with different Pcsk9tertiles. Logistic regression Model 1 was adjusted for age and body mass index (BMI). Logistic regression Model 2 was adjusted for age, BMI, familial history of PCAD, smoking, hypertension, and diabetes. Logistic regression Model 3 was adjusted for age, BMl, familial history of PCAD, smoking, hypertension, diabetes, glucose, LDL-C, and Apob

scores) in PMI patients. Particularly, Pcsk9-related coronary severity may be associated with high LDL-C levels. In addition, higher serum Pcsk9 levels had an increased risk of MACE in PMI patients after PCI intervention.

The SYNTAX score is an anatomical-based tool, which are used to objectively judge the complexity of CAD and guide the decision between CABG and PCI. Using the SYNTAX score to assess coronary severity is reasonable and meets the current guidelines, such as for use in myocardial infarction $[19,32]$. Recent studies have also shown that high levels of Pcsk9 can be considered as new and reliable biomarkers for the presence and severity of CHD $[13,23,24]$. Also, the circulating concentration of Pcsk9 increased in the first few hours/days after acute coronary syndrome (ACS) [23, 33]. Serum Pcsk9 levels are related to SYNTAX scores in patients with acute or stable CAD [20-23]. The correlation between serum Pcsk9 levels and the extent of disease in PMI patients has not been studied until now. The present study showed that, similar to patients with acute and stable CAD, medium and high Pcsk9 levels also had increased risk of increased coronary severity (SYNTAX score $>21.5$ ) in PMI patients. Simultaneously, high Pcsk9 levels were associated with increased risk of MACE after PCI intervention. As SYNTAX scores increase, the incidence of adverse long-term cardiovascular events increases, including MACE [34, 35]. Therefore, results of the present study suggest thatPcsk9-related MACE maybe associated with severe coronary artery lesions in PMI patients after PCI intervention.

In the present study, in addition to Pcsk9 levels, ApoB, creatine kinase, NT-proBnp, diabetes were also independent predictors of SYNTAX scores. In addition, significant differences were found in LDL-C levels between the three SYNTAX groups. LDL-C, ApoB and SYNTAX scores were significantly positively correlated, which is also consistent with previous research [36]. However, studies have shown that hs-Crp also correlates positively with CHD severity [37], which does not agree with results in the present study for patients with PMI. According to these findings, it suggests that severe coronary lesions in various types of CAD (e.g., ST-segment elevation myocardial infarction, stable angina pectoris) may be associated with different predictors.

Hyperlipidemia is a traditional risk in all age group of CHD, which appears to be correlated with MI [38]. Particularly, familial hyperlipidemia was associated with high prevalence of MI, with a prevalence of 38\% [39]. It also appears to exhibit higher concentrations of total cholesterol, triglyceride, and LDL-C in patients with MI $[40,41]$. Recently, association of LDL-C with MI was found in patients aged 40 years, with an adjusted OR of 5.02 compared to controls [41]. However, the present study showed that all PMI patients did not have histories of familial hypercholesterolemia and statin use, while histories of PCAD, beta-blocker use, CCB use and ARB/ ACEI use were not correlated with severity of coronary artery lesion in these patients. Although there were the associations of coronary artery lesions and LDL-C, ApoB, or lipoprotein (a) levels. Lipoprotein(a) $\geqq 60 \mathrm{mg} / \mathrm{dL}$ has been shown to be associated with MACE in patients with premature myocardial infarction [42]. However, the present study indicated that lipoprotein (a) was not associated with SYNTAX score and MACE. Furthermore, as a new risk factor for CHD, Pcsk9 could reduce liver clearance of plasma LDL-C by degrading LDL receptors [43]. Although Pcsk9 is related to the abundance of LDL receptors in liver cells, it is unclear whether the level of 
Table 3 Univariate and Multivariate Cox regression model of patients' characteristics and MACE events

\begin{tabular}{|c|c|c|c|c|}
\hline \multirow[t]{2}{*}{ Variables } & \multicolumn{2}{|l|}{ Univariate } & \multicolumn{2}{|l|}{ Multivariate } \\
\hline & HR $(95 \% \mathrm{Cl})$ & $P$-value & aHR $(95 \% \mathrm{Cl})$ & $P$-value \\
\hline Age, years & $1.07(0.98,1.18)$ & 0.150 & - & - \\
\hline Body mass index, $\mathrm{kg} / \mathrm{m}^{2}$ & $1.14(0.91,1.42)$ & 0.250 & - & - \\
\hline SBP, mmHg & $1.02(1.01,1.03)$ & $0.030^{*}$ & $1.01(0.99,1.03)$ & 0.168 \\
\hline \multicolumn{5}{|l|}{ Past history } \\
\hline Hypertension & $1.15(0.55,2.41)$ & 0.710 & - & - \\
\hline Diabetes & $1.59(0.64,3.93)$ & 0.320 & - & - \\
\hline Familial history of PCAD & $1.79(0.68,4.71)$ & 0.240 & - & - \\
\hline Smoking & $2.55(0.77,8.44)$ & 0.130 & - & - \\
\hline \multicolumn{5}{|l|}{ Biochemistry } \\
\hline White blood cells, $10^{9} / \mathrm{L}$ & $0.99(0.87,1.12)$ & 0.890 & - & - \\
\hline Urea, mmol/L & $1.22(1.01,1.48)$ & $0.047^{*}$ & $1.02(0.77,1.35)$ & 0.896 \\
\hline $\mathrm{Lp}(\mathrm{a}), \mathrm{nmol} / \mathrm{L}$ & $0.99(0.99-1.00)$ & 0.407 & - & - \\
\hline $\mathrm{TC}, \mathrm{mmol} / \mathrm{L}$ & $0.97(0.69,1.36)$ & 0.850 & - & - \\
\hline $\mathrm{LDL}-\mathrm{C}, \mathrm{mmol} / \mathrm{L}$ & $0.96(0.67,1.37)$ & 0.820 & - & - \\
\hline $\mathrm{LDL}-\mathrm{C}>2.6 \mathrm{mmol} / \mathrm{L}$ & $1.57(0.59,4.14)$ & 0.360 & - & - \\
\hline VLDL-C, mmol/L & $1.00(0.65,1.53)$ & 0.990 & - & - \\
\hline Apob, g/L & $1.10(0.32,3.83)$ & 0.880 & - & - \\
\hline $\mathrm{HDL}-\mathrm{C}, \mathrm{mmol} / \mathrm{L}$ & $1.52(0.68,5.87)$ & 0.130 & - & - \\
\hline Triglycerides, mmol/L & $1.06(0.92,1.22)$ & 0.450 & - & - \\
\hline $\mathrm{ALT}, \mathrm{U} / \mathrm{L}$ & $1.00(0.99,1.01)$ & 0.880 & - & - \\
\hline Glucose, $\mathrm{mmol} / \mathrm{L}$ & $1.07(1.00,1.13)$ & $0.040^{*}$ & $0.99(0.93,1.08)$ & 0.977 \\
\hline Creatinine, $\mu \mathrm{mol} / \mathrm{L}$ & $1.02(1.01,1.03)$ & $<0.001^{*}$ & $1.01(0.98,1.03)$ & 0.592 \\
\hline \multicolumn{5}{|l|}{ Ischemic heart disease } \\
\hline LVEF, \% & $0.99(0.94,1.04)$ & 0.560 & - & - \\
\hline Creatine kinase, U/L & $1.00(1.00,1.00)$ & 0.950 & - & - \\
\hline $\mathrm{c}-\mathrm{Tnt}, \mathrm{ng} / \mathrm{Ml}$ & $1.03(0.92,1.16)$ & 0.590 & - & - \\
\hline hs-Crp, mg/L & $1.00(0.99,1.01)$ & 0.910 & - & - \\
\hline NT-proBnp, pg/mL & $1.00(1.00,1.00)$ & 0.170 & - & - \\
\hline SYNTAX score > 21.5 & $1.01(0.97,1.06)$ & 0.540 & - & - \\
\hline SYNTAX score & $1.13(0.52,2.45)$ & 0.750 & - & - \\
\hline \multicolumn{5}{|l|}{ Biomarker } \\
\hline Pcsk9, ng/mL & $1.01(1.004,1.011)$ & $<0.001^{*}$ & $1.01(1.00,1.01)$ & $<0.001^{*}$ \\
\hline$<122.92$ & Ref. & Ref. & & \\
\hline $122.92-204.13$ & $0.15(0.57,4.10)$ & 0.400 & - & - \\
\hline$\geqq 204.13$ & $2.28(0.90,5.82)$ & 0.080 & - & - \\
\hline
\end{tabular}

Variables are presented as adjusted hazard ratio (aHR), $95 \%$ confidence interval $(95 \% \mathrm{Cl}), P$-values were derived from univariate or multivariate analysis. ${ }^{*} P<0.05$ $S B P$ systolic blood pressure, $P C A D$ premature coronary artery disease, $L p(a)$ Lipoprotein a, $T C$ total cholesterol, $L D L-C$ low density lipoprotein cholesterol, $A p o b$ apolipoprotein $\mathrm{B}, H D L-C$ high density lipoprotein cholesterol, $A L T$ alanine transaminase, $L V E F$ left ventricular ejection fraction, $h s$-Crp high-sensitivity C-reactive protein, c-Tnt cardiac Troponin T, NT-proBnp N-terminal pro-B type natriuretic peptide, Pcsk9 proprotein convertase subtilisin/kexin type 9

Pcsk9 directly reflects the activity of LDL receptors [20]. Studies have shown that Pcsk9 may speed up atherosclerosis due to promote inflammation, endothelial cell function and hypertension, and that its mechanism is not related to LDL-R [44]. Therefore, Pcsk9 may be directly related to atherosclerosis development [20, 45]. Regarding possible direct atherosclerotic effects of Pcsk9, distinguishing the roles of Pcsk9 from those of LDL-C will be difficult, because it interferes with cholesterol metabolism very rapidly by enhancing LDLR degradation 
at different tissue levels [23]. Interestingly, the present study showed that, after stratifying by serum LDL-C level, medium-high Pcsk9 levels were only correlated with greater risk of high SYNTAX scores in patients with high LDL-C level, in whom this observation was not found. According to these findings, Pcsk9-related severe coronary artery lesions in PMI patients did not relate to familial hyperlipidemia and may be caused by the effects of Pcsk9 on LDL receptors, resulting in increased serum LDL-C levels.

Due to the lack of clinical variables and a lack of personalized decision-making methods, the limitations of the SYNTAX score in helping decision-making between CABG and PCI have be-come obvious [34]. Combining clinical grammatical variables with clinical variables to facilitate decision-making be-tween CABG and PCI may ultimately result in improved SYNTAX scores (e.g., logistic clinical SYNTAX scores), which can objectively make tailored decisions for individual patients [34, 46]. Compared to SYNTAX score alone, the Logistic Clinical SYNTAX Score (combination of SYNTAX score, age, creatinine clearance, and LV ejection fraction) has been demonstrated to improve the prediction of mortality in subjects with complex coronary artery disease [6]. In the present study, serum Pcsk9 levels were associated with SYNTAX scores and MACE, but based on these studies, suggesting that serum Pcsk9 levels may be combined with SYNTAX scores and other variables to develop a new modified SYNTAX score to improve MACE predictions in PMI patients undergoing PCI intervention in the future.

More and more clinical applications of Pcsk9 inhibitors reported in numerous related studies show that they have a significant efficacy on reducing LDL-C and even on regression of coronary plaque. As novel lipidlowering drugs, Pcsk9 inhibitors bind to LDL receptor on the surface of the hepatocytes, allowing more of these LDL receptors to clear LDL-C from the blood. Studies have shown that the Pcsk9 inhibitor evolocumab reduced LDL-C levels by about $60 \%$ [47]. In the GLAGOV trial [48], 64\% of patients with ACS who were treated with combined statins and evolocumab achieved plaque regression after 78 weeks as examined by intravascular ultrasonography (IVUS). A recent study examined the effects of evolocumab on the extent of atherosclerotic plaque in ACS patients through serial optical coherence tomography (OCT) analysis, finding that the addition of evolocumab to statin therapy may increase fibrous cap thickness and regression of lipid-rich plaques [49], which may reduce the risk of atherosclerosis plaque ruptures. Taken together, these studies provide strong evidence supporting the current findings about associations between Pcsk9 and coronary artery lesions, providing guidance for clinical applications of Pcsk9 inhibitor.

\section{Study strength and limitations}

The data of the present study will help to further optimize risk stratification of coronary heart disease and provide more scientific and reasonable evidence for clinical application of Pcsk9 inhibitors, especially among young people. This will also contribute to improving the prognosis of PMI patients and help to reduce the related disability and mortality. It looks forward to implementing more large-sample, multi-center prospective studies. Nevertheless, several limitations of this study must be acknowledged. First, this single-center analysis may not completely exclude the selection bias, which may partially explain some statistically insignificant correlations in this study. Therefore, it still remains necessary to perform a large-scale and prospective multi-center study to confirm the results of the present study. Second, female was excluded from this study because the number of MACE of female patients are not inadaptable to perform the analysis of regression model. Third, this is a crosssectional study that can only establish associations, not cause-and-effect associations. Also, the MACE results were not obtained in 16 patients who either declined to answer follow-up calls or had provided incorrect telephone numbers, which may have interfered with analysis. Finally, the lack of endovascular imaging techniques that are more sensitive to detecting atherosclerosis limits exploration of this topic.

\section{Conclusions}

Serum Pcsk9 levels are correlated to the extent of coronary artery lesions in PMI patients, especially in patients with high LDL-C. Moreover, high Pcsk9 levels are associated with risk of MACE in these patients after PCI intervention. This suggests that serum Pcsk9 may be as a biomarker for coronary artery lesion severity and may contribute to risk stratification in PMI patients, while providing guidance for clinical application of Pcsk9 inhibitors.

\section{Abbreviations \\ Pcsk9: Proprotein convertase subtilisin/kexin type 9; PMl: Premature myocardial infarction; CAG: Coronary angiography; PCI: Percutaneous coronary intervention; SYNTAX: SYNergy between percutaneous coronary intervention with [paclitaxel-eluting] TAXUS stent and cardiac surgery; LDL: Low-density lipoprotein; Apob: Apolipoprotein B; NT-proBnp: N-terminal pro-brain natriuretic peptide; CK: Creatine kinase; MACE: Major adverse cardiac events; NSTEMI: Non-ST elevation myocardial infarction; STEMI: ST- elevation myocardial infarction; CAD: Coronary artery disease; SBP: Systolic blood pressure; LVEF: Left ventricular ejection fraction (LVEF); BUN: Blood urea nitrogen}

\section{Supplementary Information}

The online version contains supplementary material available at https://doi. org/10.1186/s12944-021-01478-w.

Additional file 1: Supplementary Table 1. Multivariate logistic regression model of PCsk9 and SYNTAX score after classifying by LDL-C 
levels. Supplementary Table 2. Baseline characteristics of patients with premature MI. Supplementary Figure 1. ROC curve analysis of predictive marker Pcsk9 for identifying the occurrence of high SYNTAX score. Supplementary Figure 2. Comparison of 1-year cardiovascular events of PMI between patients with low, medium and high Pcsk9 levels. Patients were stratified according to T1 $(<122.92 \mathrm{ng} / \mathrm{mL}), \mathrm{T} 2(122.92-204.13$ $\mathrm{ng} / \mathrm{mL})$, and T3 ( $\geqq 204.13 \mathrm{ng} / \mathrm{mL}$ ) for serum pcsk9 level.

\section{Acknowledgements}

The authors wish to thank Tianjin Chest Hospital Biobank for providing standardized frozen plasma samples, and we especially thank the enrolled patients for their participation.

\section{Authors' contributions}

$J G$ and YL had made substantial contributions to the conception and the study design; JG, YNY, JM, CPL, and YL preformed the experimental studies; YNY collected the data; SYF and CPL analyzed the data; JG, ZC and YNY prepared the manuscript; all authors read and approved the final version for submission.

\section{Funding}

This research project was funded, in part, by the Key Project of Scientific and Technological Support Plan of Tianjin in 2020 (No.20YFZCSY00820); Major Science and Technology Projects of Tianjin Science and Technology Commission in 2016 (No. 16ZXMJSY00150); The National 135 Key Research and Development Program in 2016 (No.2016YFC1301203).

\section{Availability of data and materials}

The data used to support the findings of this study are included within the article and its supplementary information files.

\section{Declarations}

\section{Ethics approval and consent to participate}

The study protocol was approved by the Ethics Committee of Tianjin Chest Hospital (No. 2017KY-007-01) and all included patients provided signed informed consent prior to study participation.

\section{Consent for publication}

Not applicable.

\section{Competing interests}

The authors declare that they have no competing interests.

\section{Author details}

${ }^{1}$ Chest Hospital, Tianjin University, No.92 Weijin Road Nankai District, Tianjin 300072, P.R. China. ${ }^{2}$ Thoracic Clinical College, Tianjin Medical University, No.22 Qi xiang tai Road, Heping District, Tianjin 300070, P.R. China. ${ }^{3}$ Cardiovascular Institute, Tianjin Chest Hospital, No.261 Tai erzhuang Road, Jinnan District, Tianjin 300222, P.R. China. ${ }^{4}$ Tianjin Medical University, No.22 Qi xiangtai Road, Heping District, Tianjin 300070, P.R. China. ${ }^{5}$ Department of Cardiology, Tianjin Chest Hospital, No.261 Tai erzhuang Road, Jinnan District, Tianjin 300222, P.R. China.

\section{Received: 23 February 2021 Accepted: 6 May 2021}

Published online: 27 May 2021

\section{References}

1. Zhang Q, Zhao D, Xie W, Xie X, Guo M, Wang M, et al. Recent trends in hospitalization for acute myocardial infarction in Beijing: increasing overall burden and a transition from ST-segment elevation to non-ST-segment elevation myocardial infarction in a population-based study. Medicine (Baltimore). 2016;95(5):e2677. https://doi.org/10.1097/MD.0000000000002677.

2. Zhou Y, Yao X, Liu G, Jian W, Yip W. Level and variation on quality of care in China: a cross-sectional study for the acute myocardial infarction patients in tertiary hospitals in Beijing. BMC Health Serv Res. 2019;19(1):43. https://doi. org/10.1186/s12913-019-3872-0.

3. Titov BV, Osmak GJ, Matveeva NA, Kukava NG, Shakhnovich RM, Favorov AV, et al. Genetic risk factors for myocardial infarction more clearly manifest for early age of first onset. Mol Biol Rep. 2017;44(4):315-21. https://doi.org/10.1 007/s11033-017-4112-5.

4. Dugani SB, Ayala Melendez AP, Reka R, Hydoub YM, McCafferty SN, Murad $\mathrm{MH}$, et al. Risk factors associated with premature myocardial infarction: a systematic review protocol. BMJ Open. 2019;9(2):e023647. https://doi.org/1 0.1136/bmjopen-2018-023647.

5. Arora S, Stouffer GA, Kucharska-Newton AM, Qamar A, Vaduganathan M, Pandey $A$, et al. Twenty year trends and sex differences in young adults hospitalized with acute myocardial infarction. Circulation. 2019;139(8):104756. https://doi.org/10.1161/CIRCULATIONAHA.118.037137.

6. Fischer M, Broeckel U, Holmer S, Baessler A, Hengstenberg C, Mayer B, et al. Distinct heritable patterns of angiographic coronary artery disease in families with myocardial infarction. Circulation. 2005;111(7):855-62. https:// doi.org/10.1161/01.CIR.0000155611.41961.BB.

7. Braenne I, Kleinecke M, Reiz B, Graf E, Strom T, Wieland T, et al. Systematic analysis of variants related to familial hypercholesterolemia in families with premature myocardial infarction. Eur J Hum Genet. 2016;24(2):191-7. https:// doi.org/10.1038/ejhg.2015.100.

8. Guella I, Asselta R, Ardissino D, Merlini PA, Peyvandi F, Kathiresan S, et al. Effects of PCSK9 genetic variants on plasma LDL cholesterol levels and risk of premature myocardial infarction in the Italian population. J Lipid Res. 2010;51(11):3342-9. https://doi.org/10.1194/jlr.M010009.

9. Lee C, Cui Y, Song J, Li S, Zhang F, Wu M, et al. Effects of familial hypercholesterolemia-associated genes on the phenotype of premature myocardial infarction. Lipids Health Dis. 2019;18(1):95. https://doi.org/10.11 86/s12944-019-1042-3.

10. Lambert G, Charlton F, Rye KA, Piper DE. Molecular basis of PCSK9 function. Atherosclerosis. 2009;203(1):1-7. https://doi.org/10.1016/j.atherosclerosis.2 008.06.010.

11. Liu X, Suo R, Chan CZY, Liu T, Tse G, Li G. The immune functions of PCSK9: local and systemic perspectives. J Cell Physiol. 2019;234(11):19180-8. https:// doi.org/10.1002/jcp.28612.

12. Denis M, Marcinkiewicz J, Zaid A, Gauthier D, Poirier S, Lazure C, et al. Gene inactivation of proprotein convertase subtilisin/kexin type 9 reduces atherosclerosis in mice. Circulation. 2012;125(7):894-901. https://doi.org/1 0.1161/CIRCULATIONAHA.111.057406.

13. Leander K, Malarstig A, Van't Hooft FM, Hyde C, Hellenius ML, Troutt JS, et al. Circulating Proprotein Convertase Subtilisin/Kexin type 9 (PCSK9) predicts future risk of cardiovascular events independently of established risk factors. Circulation. 2016;133(13):1230-9. https://doi.org/10.1161/ CIRCULATIONAHA.115.018531.

14. Li S, Li JJ. PCSK9: a key factor modulating atherosclerosis. J Atheroscler Thromb. 2015;22(3):221-30. https://doi.org/10.5551/jat.27615.

15. Khan SU, Talluri S, Riaz H, Rahman H, Nasir F, Bin Riaz I, et al. A Bayesian network meta-analysis of PCSK9 inhibitors, statins and ezetimibe with or without statins for cardiovascular outcomes. Eur J Prev Cardiol. 2018;25(8): 844-53. https://doi.org/10.1177/2047487318766612.

16. Ridker PM, Rose LM, Kastelein JJP, Santos RD, Wei C, Revkin J, et al. Cardiovascular event reduction with PCSK9 inhibition among 1578 patients with familial hypercholesterolemia: results from the SPIRE randomized trials of bococizumab. J Clin Lipidol. 2018;12(4):958-65. https://doi.org/10.1016/j.jacl.2018.03.088.

17. Capodanno D, Di Salvo ME, Cincotta G, Miano M, Tamburino C, Tamburino C. Usefulness of the SYNTAX score for predicting clinical outcome after percutaneous coronary intervention of unprotected left main coronary artery disease. Circ Cardiovasc Interv. 2009;2(4):302-8. https://doi.org/10.11 61/CIRCINTERVENTIONS.108.847137.

18. Huang $\mathrm{G}$, Zhao JL, Du H, Lan XB, Yin YH. Coronary score adds prognostic information for patients with acute coronary syndrome. Circ J. 2010;74(3): 490-5. https://doi.org/10.1253/circj.CJ-09-0637.

19. Neumann FJ, Sousa-Uva M, Ahlsson A, Alfonso F, Banning AP, Benedetto U, et al. 2018 ESC/EACTS Guidelines on myocardial revascularization. Eur Heart J. 2019;40(2):87-165. https://doi.org/10.1093/eurheartj/ehy394.

20. Bae KH, Kim SW, Choi YK, Seo JB, Kim N, Kim CY, et al. Serum levels of PCSK9 are associated with coronary angiographic severity in patients with acute coronary syndrome. Diabetes Metab J. 2018;42(3):207-14. https://doi. org/10.4093/dmj.2017.0081.

21. Dalgic Y, Abaci O, Kocas C, Cetinkal G, Dalgic SN, Buyuk A, et al. The relationship between protein convertase subtilisin kexin type-9 levels and extent of coronary artery disease in patients with non-ST-elevation myocardial infarction. Coron Artery Dis. 2020;31(1):81-6. https://doi.org/10.1 097/MCA.0000000000000774. 
22. Li JJ, Li S, Zhang Y, Xu RX, Guo YL, Zhu CG, et al. Proprotein Convertase Subtilisin/Kexin type 9, C-reactive protein, coronary severity, and outcomes in patients with stable coronary artery disease: a prospective observational cohort study. Medicine (Baltimore). 2015;94(52):e2426. https://doi.org/10.1 097/MD.0000000000002426.

23. Panahi $Y$, Ghahrodi MS, Jamshir M, Safarpour MA, Bianconi V, Pirro M, et al. PCSK9 and atherosclerosis burden in the coronary arteries of patients undergoing coronary angiography. Clin Biochem. 2019;74:12-8. https://doi. org/10.1016/j.clinbiochem.2019.09.001.

24. Wang $S$, Cheng ZY, Zhao ZN, Quan XQ, Wei Y, Xia DS, et al. Correlation of serum PCSK9 in CHD patients with the severity of coronary arterial lesions. Eur Rev Med Pharmacol Sci. 2016;20(6):1135-9.

25. Li S, Guo YL, Xu RX, Zhang Y, Zhu CG, Sun J, et al. Plasma PCSK9 levels are associated with the severity of coronary stenosis in patients with atherosclerosis. Int J Cardiol. 2014;174(3):863-4. https://doi.org/10.1016/j.ijca rd.2014.04.224

26. Thygesen K, Alpert JS, Jaffe AS, Chaitman BR, Bax JJ, Morrow DA, et al. Fourth universal definition of myocardial infarction (2018). Eur Heart J. 2019; 40(3):237-69. https://doi.org/10.1093/eurheartj/ehy462.

27. Williams B, Mancia G, Spiering W, Agabiti Rosei E, Azizi M, Burnier M, et al. 2018 ESC/ESH guidelines for the management of arterial hypertension. Eur Heart J. 2018;39(33):3021-104. https://doi.org/10.1093/eurheartj/ehy339.

28. American DA. 2. Classification and diagnosis of diabetes: standards of medical Care in Diabetes-2019. Diabetes Care. 2019;42(Suppl 1):S13-28. https://doi.org/10.2337/dc19-S002.

29. Cesaroni G, Forastiere F, Agabiti N, Valente P, Zuccaro P, Perucci CA. Effect of the Italian smoking ban on population rates of acute coronary events. Circulation. 2008;117(9):1183-8. https://doi.org/10.1161/CIRCULATIONAHA. 07.729889 .

30. Organization WH. The top 10 causes of death: World Health Organization; 2018 [updated May 24, 2018. Available from: https://www.who.int/newsroom/fact-sheets/detail/the-top-10-causes-of-death.

31. Gao XJ, Yang JG, Yang YJ, Li W, Xu HY, Wu Y, et al. Age-related coronary risk factors in Chinese patients with acute myocardial infarction. Zhonghua Yi Xue Za Zhi. 2016;96(40):3251-6. https://doi.org/10.3760/cma.j.issn.0376-24 91.2016.40.012.

32. Tandjung K, Lam MK, Sen H, de Man FH, Louwerenburg JH, Stoel MG, et al. Value of the SYNTAX score for periprocedural myocardial infarction according to $\mathrm{WHO}$ and the third universal definition of myocardial infarction: insights from the TWENTE trial. Eurolntervention. 2016;12(4):43140. https://doi.org/10.4244/EIJY15M08_01.

33. Gencer B, Montecucco F, Nanchen D, Carbone F, Klingenberg R, Vuilleumier $\mathrm{N}$, et al. Prognostic value of PCSK9 levels in patients with acute coronary syndromes. Eur Heart J. 2016;37(6):546-53. https://doi.org/10.1093/eurheartj/ ehv637.

34. Farooq V, Head SJ, Kappetein AP, Serruys PW. Widening clinical applications of the SYNTAX score. Heart. 2014;100(4):276-87. https://doi.org/10.1136/hea rtjinl-2013-304273.

35. Serruys PW, Morice MC, Kappetein AP, Colombo A, Holmes DR, Mack MJ, et al. Percutaneous coronary intervention versus coronary-artery bypass grafting for severe coronary artery disease. N Engl J Med. 2009;360(10):96172. https://doi.org/10.1056/NEJMoa0804626.

36. Lin T, Wang L, Guo J, Liu P, Chen L, Wei M, et al. Association between serum LDL-C and ApoB and SYNTAX score in patients with stable coronary artery disease. Angiology. 2018;69(8):724-9. https://doi.org/10.1177/000331 9717748771

37. Li C, Zhang Z, Peng Y, Gao H, Wang Y, Zhao J, et al. Plasma neutrophil gelatinase-associated lipocalin levels are associated with the presence and severity of coronary heart disease. PLoS One. 2019;14(8):e0220841. https:// doi.org/10.1371/journal.pone.0220841.

38. Incalcaterra E, Caruso M, Lo Presti R, Caimi G. Myocardial infarction in young adults: risk factors, clinical characteristics and prognosis according to our experience. Clin Ter. 2013;164(2):e77-82. https://doi.org/10.7417/CT.2013.1535.

39. Wiesbauer F, Blessberger H, Azar D, Goliasch G, Wagner O, Gerhold L, et al. Familial-combined hyperlipidaemia in very young myocardial infarction survivors (< or $=40$ years of age). Eur Heart J. 2009;30(9):1073-9. https://doi. org/10.1093/eurheartj/ehp051.

40. Chan CM, Chen WL, Kuo HY, Huang CC, Shen YS, Choy CS, et al. Circadian variation of acute myocardial infarction in young people. Am J Emerg Med. 2012;30(8):1461-5. https://doi.org/10.1016/j.ajem.2011.11.019.
41. Goliasch G, Oravec S, Blessberger H, Dostal E, Hoke M, Wojta J, et al. Relative importance of different lipid risk factors for the development of myocardial infarction at a very young age $(</=40$ years of age). Eur J Clin Investig. 2012;42(6):631-6. https://doi.org/10.1111/j.1365-2362.2011.02629.x.

42. Gragnano F, Fimiani F, Di Maio M, Cesaro A, Limongelli G, Cattano D, et al. Impact of lipoprotein(a) levels on recurrent cardiovascular events in patients with premature coronary artery disease. Intern Emerg Med. 2019;14(4):6215. https://doi.org/10.1007/s11739-019-02082-8.

43. Stein EA, Raal FJ. New therapies for reducing low-density lipoprotein cholesterol. Endocrinol Metab Clin N Am. 2014;43(4):1007-33. https://doi. org/10.1016/j.ecl.2014.08.008.

44. Urban D, Poss J, Bohm M, Laufs U. Targeting the proprotein convertase subtilisin/kexin type 9 for the treatment of dyslipidemia and atherosclerosis. J Am Coll Cardiol. 2013;62(16):1401-8. https://doi.org/10.1016/j.jacc.2013.07.056.

45. Cohen JC, Boerwinkle E, Mosley TH Jr, Hobbs HH. Sequence variations in PCSK9, low LDL, and protection against coronary heart disease. N Engl J Med. 2006;354(12):1264-72. https://doi.org/10.1056/NEJMoa054013.

46. Capodanno D, Caggegi A, Miano M, Cincotta G, Dipasqua F, Giacchi G, et al. Global risk classification and clinical SYNTAX (synergy between percutaneous coronary intervention with TAXUS and cardiac surgery) score in patients undergoing percutaneous or surgical left main revascularization. JACC Cardiovasc Interv. 2011;4(3):287-97. https://doi.org/10.1016/j.jcin.2010.10.013.

47. Koren MJ, Lundqvist P, Bolognese M, Neutel JM, Monsalvo ML, Yang J, et al. Anti-PCSK9 monotherapy for hypercholesterolemia: the MENDEL-2 randomized, controlled phase III clinical trial of evolocumab. J Am Coll Cardiol. 2014;63(23):2531-40. https://doi.org/10.1016/j.jacc.2014.03.018.

48. Nicholls SJ, Puri R, Anderson T, Ballantyne CM, Cho L, Kastelein JJ, et al. Effect of Evolocumab on progression of coronary disease in statin-treated patients: the GLAGOV randomized clinical trial. JAMA. 2016;316(22):2373-84. https://doi.org/10.1001/jama.2016.16951.

49. Yano H, Horinaka S, Ishimitsu T. Effect of evolocumab therapy on coronary fibrous cap thickness assessed by optical coherence tomography in patients with acute coronary syndrome. J Cardiol. 2020;75(3):289-95. https://doi. org/10.1016/j.jjcc.2019.08.002

\section{Publisher's Note}

Springer Nature remains neutral with regard to jurisdictional claims in published maps and institutional affiliations.

Ready to submit your research? Choose BMC and benefit from:

- fast, convenient online submission

- thorough peer review by experienced researchers in your field

- rapid publication on acceptance

- support for research data, including large and complex data types

- gold Open Access which fosters wider collaboration and increased citations

- maximum visibility for your research: over $100 \mathrm{M}$ website views per year

At BMC, research is always in progress.

Learn more biomedcentral.com/submissions 